\title{
THE SHORT-TERM METABOLIC EFFECTS OF STRENUOUS EXERCISE IN BODYBUILDERS
}

\author{
G. McKILLOP, F. C. BALLANTYNE*, W. BORLAND*, R. SCULLION, J. W. KAY**, G. S. FELL* and D. BALLANTYNE \\ Departments of Medical Cardiology and Haematology, Victoria Infirmary Glasgow, *Department of Biochemistry, Royal Infirmary, Glasgow \\ and **Department of Statistics, University of Glasgow, Glasgow
}

\section{INTRODUCTION}

The metabolic response to acute exercise has been studied mainly in dynamic sports, e.g. jogging (Findlay et al, 1987). There are few descriptions of the effects of power sports e.g. weightlifting (Hurley et al, 1987).

Bodybuilding is a particularly intense form of exercise. Since it has been shown that other forms of exercise produce biochemical effects we decided to investigate bodybuilders. There is debate about whether exercise produces an "acute phase response" (Myers et al, 1987), i.e. a series of physiological and biochemical changes which occur after tissue injury or infection (Fleck, 1988). We measured plasma proteins and trace elements which change in concentration during the acute phase response. These were albumin, caeruloplasmin, C-reactive protein, zinc and copper. Glucose, lactate, ketones and electrolytes were also measured.

\section{SUBJECTS AND METHODS}

Four male bodybuilders (age 23-31 years) were studied. All had been training regularly ( $>8$ hours per week) for at least 4 years. None was taking anabolic drugs. All consented to undergo an exercise programme. This was a "whole body" programme in which all the major muscle groups (chest, back, shoulders, legs, biceps and triceps) were exercised in a "super-set" fashion. One set of exercises for one body part was performed followed by a different exercise for the same area and this pairing was repeated on five occasions i.e. five super-sets per body part. The exercises were performed on a Universal Multigym, with which all four subjects were familiar and each subject did the same series of exercises. It is difficult to derive a formula to standardise the workload of a super-set programme for each subject, therefore all subjects were asked to train at their maximum level, which was their normal practice, using their training log books as reference. This programme, which was similar to their own training programme, was completed within 60 minutes and was followed by a recovery period of 60 minutes. During this period venesection was carried out at 0 (prior to exercise), 45, 60, 63, 66, 70, 90 and 120 minutes via an in-dwelling venous cannula. At each time $15 \mathrm{ml}$ of blood were withdrawn. One millilitre was preserved in a fluoride/ oxalate container (for glucose and lactate). For ketones $5 \mathrm{ml}$ was added to a tube containing $5 \mathrm{ml}$ ice-cold $1.0 \mathrm{~mol} . \mathrm{I}^{-1}$ perchloric acid and after centrifugation the supernatant was neutralised. The remainder of the blood was allowed to clot in a plain container and the serum used for all other analyses. Glucose was measured by a glucose oxidase method. Lactate, acetoacetate and 3-hydroxybutyrate were measured enzymatically by changes in the absorbance of $\mathrm{NAD} / \mathrm{NADH}$. Sodium, potassium, chloride, $\mathrm{CO}_{2}$, urea, creatinine, calcium, phosphate and albumin were analysed by a Technicon SMAC II. Alkaline phosphatase (ALP),

Address for correspondence:

Dr. G. McKillop

Division of Clinical Medicine

Victoria Infirmary

Glasgow G42 9TY aspartate transaminase (AST), alanine transaminase (ALT), lactate dehydrogenase (LD) and creatine kinase (CK) were measured by centrifugal analysis. C-reactive protein (CRP) was measured by immunofluorimetry, transferrin and caeruloplasmin by immunoturbidimetry and zinc and copper by atomic absorption spectrophotometry.

Due to the small sample size, assumptions required to perform t-tests are not met. Hence, we present a descriptive analysis.

\section{RESULTS}

As shown in Table I, all analytes were initially within appropriate reference ranges with the exception of $C K$.

No change occurred in haematocrit, but there was a rise in plasma albumin at 45 and 60 minutes of exercise. Glucose did not change during the study. Lactate levels rose markedly. Preliminary studies showed that the peak occurred at 30-45 minutes of exercise. This rise in lactate was accompanied by a fall in $\mathrm{CO}_{2}$ content and entirely accounted for the rise in the cation-anion gap. 3-hydroxybutyrate rose during the study, but there was no change in aceto-acetate.

There was no change in sodium, potassium, chloride or urea, but creatinine did rise on exercise. Phosphate fell during the recovery period. There was no change in calcium. AST rose at $\mathbf{4 5}$ minutes and remained so until $\mathbf{7 0}$ minutes. CK was increased at the start of the study (reference value $<150 \mathrm{U} . \mathrm{I}^{-1}$ ), and remained elevated throughout the period of study. There was no change in LD or ALT. Albumin rose during the exercise period. CRP, caeruloplasmin and transferrin did not change. Both plasma zinc and the zinc/albumin ratio fell from 60 minutes onwards. There was no change in copper or the copper/ caeruloplasmin ratio.

\section{DISCUSSION}

There was no rise in haematocrit or urea to support an element of dehydration, although the albumin did rise. This would therefore make a pre-renal (dehydration) explanation for the rise in creatinine unlikely. Creatinine is a normal metabolite of muscle creatine and it is possible that in men with such a large muscle bulk such intense exercise may lead to an increased release into plasma of creatinine.

The plasma lactate concentration on exercise represents a balance between several factors including efflux from skeletal muscle and uptake by liver. The elevations in lactate concentration in the present study are greater than in many other forms of exercise. Lactic acidosis impairs muscle function, but despite their high lactate levels these subjects were able to continue to exercise, although they found it difficult to sustain the same initial intensity. This may have contributed to the fall in lactate between $\mathbf{4 5}$ and 60 minutes. The rise in 3-hydroxybutyrate without any consistent change in aceto-acetate may indicate some increase in fat metabolism but this is less marked than the increase in carbohydrate metabolism.

The lack of change in potassium levels despite the profound lactic acidosis is further evidence that the view that in metabolic acidosis hydrogen ions exchange for 
TABLE I

Effect of one hour's training on median (range) concentrations of metabolites in four bodybuilders

\begin{tabular}{|c|c|c|c|c|c|c|c|c|}
\hline & \multirow[b]{2}{*}{ Basal } & \multicolumn{2}{|c|}{ Exercise } & \multicolumn{5}{|c|}{ Recovery } \\
\hline & & $45 \mathrm{~min}$ & $60 \mathrm{~min}$ & $63 \mathrm{~min}$ & $66 \mathrm{~min}$ & $70 \mathrm{~min}$ & $90 \mathrm{~min}$ & $120 \mathrm{~min}$ \\
\hline $\begin{array}{l}\text { Lactate } \\
\quad\left(\mathrm{mmol} .1^{-1}\right)\end{array}$ & $2.4(1.4-3.2)$ & $14.1(13.7-18.3)$ & $12.0(9.3-13.9)$ & $10.2(8.7-11.6)$ & $8.3(7.3-10.5)$ & $7.6(4.8-8.1)$ & $4.2(3.0-4.9)$ & $2.7(1.7-2.9)$ \\
\hline $\begin{array}{l}\text { 3-hydroxybutyrate } \\
\text { ( } \mu \mathrm{mol} .)^{-1}\end{array}$ & $32.0(26-54)$ & $50.0(38-87)$ & $49.0(42-83)$ & $52.0(45-87)$ & $52.0(47-91)$ & $45.0(44-110)$ & $46.0(37-72)$ & $53.0(36-66)$ \\
\hline $\begin{array}{l}\mathrm{CO}_{2} \text { content } \\
\left(\mathrm{mmol} .1^{-1}\right)\end{array}$ & $23.0(22-29)$ & $11.0(10-12)$ & $15.0(12-17)$ & $16.0(15-17)$ & $16.0(12-18)$ & $19.0(18-21)$ & $22.0(18-22)$ & $22.0(16-24)$ \\
\hline $\begin{array}{l}\text { Creatinine } \\
\quad\left(\mu \mathrm{mol} . \mathrm{I}^{-1}\right)\end{array}$ & $95.0(85-100)$ & $115.0(110-130)$ & $110.0(110-130)$ & $110.0(110-120)$ & $110.0(100-120)$ & $105.0(100-110)$ & $98.0(95-110)$ & $95.0(90-100)$ \\
\hline $\begin{array}{l}\text { Phosphate } \\
\text { (mmol. }\left.\right|^{-1)}\end{array}$ & $1.05(0.85-1.11)$ & $1.5(110-130)$ & $0.85(0.70-1.25)$ & $0.75(0.60-1.15)$ & $0.68(0.60-1.05)$ & $0.63(0.50-0.95)$ & $0.65(0.50-0.90)$ & $0.78(0.60-0.85)$ \\
\hline AST (U. I-1) & $40.0(29-41)$ & $72.0(65-73)$ & $65.0(61-69)$ & $65.0(56-71)$ & $64.0(56-80)$ & $54.0(42-62)$ & $48.0(33-62)$ & $42.0(28-54)$ \\
\hline CK $\left(U . I^{-1}\right)$ & $318.0(112-345)$ & $365.0(165-435)$ & $360.0(170-435)$ & $360.0(170-435)$ & $360.0(175-430)$ & $335.0(185-395)$ & $358.0(175-390)$ & $345.0(180-415)$ \\
\hline Albumin $\left(g . I^{-1}\right)$ & $46.0(45-50)$ & $51.0(49-56)$ & $48.0(47-55)$ & $48.0(46-50)$ & $47.0(45-54)$ & $47.0(46-51)$ & $47.0(45-49)$ & $47.0(46-47)$ \\
\hline Zinc $\left(\mu \mathrm{mol} . \mathrm{I}^{-1}\right)$ & $16.3(13.0-17.0)$ & $15.0(13.0-16.0)$ & $14.5(12.5-15.0)$ & $14.0(12.5-15.6)$ & $13.5(12.5-15.0)$ & $13.5(12.5-14.0)$ & $13.3(12.5-14.5)$ & $12.5(11.5-15.0)$ \\
\hline
\end{tabular}

potassium ions across cell membranes is an over simplification (Editorial, The Lancet, 1986). The fall in phosphate levels during the recovery period may indicate an intracellular phosphate shift in order to replenish high energy phosphate stores. The rise in AST during and immediately after exercise presumably reflects a "leak" in muscle cellular enzymes into plasma. Regular training decreases the CK response to exercise but does not completely abolish it (Clarkson et al, 1987). The elevated CK concentrations prior to the acute exercise in these bodybuilders may therefore reflect the response to recent periods of training. They may also be influenced by the subjects' muscle bulk. It is not possible to say whether CK showed a further significant rise during acute exercise.

There is disagreement about the ability of exercise to produce an acute phase response (Myers et al, 1987). Any fall in albumin or transferrin and rise in C-reactive protein or caeruloplasmin would not have occurred during the one hour recovery time used in our study. However, plasma zinc and the zinc/albumin ratio fell significantly from the end of exercise. A fall in zinc has also been observed 6 hours after cycling (Myers et al, 1987) but was considered to be probably due to the circadian rhythm of this cation. Our data may support the opinion that changes can occur in zinc metabolism prior to the acute phase protein response.
This study in bodybuilders shows biochemical changes in response to exercise especially in terms of blood lactate acid and plasma zinc concentrations.

\section{ACKNOWLEDGEMENT}

Supported in part by a grant from the Scottish Hospitals Endowment Research Trust.

\section{References}

Clarkson, P. M., Byrnes, W. C., Gillison, E. and Harpet, E., 1987 "Adaptation to exercise induced muscle damage". Clin.Sci. 73: 383-386.

Editorial, 1986 "Hyperkalaemia in diabetic ketoacidosis". Lancet 2: 845-846.

Findlay, I. N., Taylor, R. S., Dargie, H. J., Grant, S., Pettigrew, A. R., Wilson, J. T., Aitchison, T., Cleland, J. G. F., Elliot, A. T., Fisher, B. M., Gillen, G., Manzie, A., Rumley, A. G. and Durnin, J. V. G. A., 1987 "Cardiovascular effects of training for a marathon run in unfit middle-aged men". Br.Med.J. 295: 521-524.

Fleck, A., 1988 "Acute phase response: implications for nutrition and recovery". Nutrition 4: 109-117.

Hurley, B. F., Hagberg, J. M., Seals, D. R., Ehsani, A. A., Goldberg, A. P. and Holloszy, J. O., 1987 "Glucose tolerance and lipid-lipoprotein levels in middle-aged powerlifters". Clin.Physiol. 7: 11-19.

Myers, M. A., Nagendran, V. and Fleck, A., 1987 “Exercise does not induce an acute phase response". Ann.Clin.Biochem. 24: Suppl. 128-130.

\section{Title:}

\section{BOOK REVIEW}

Editors:

\section{OPERATIVE APPROACHES IN ORTHOPAEDIC SURGERY AND TRAUMATOLOGY}

Publishers: $\quad$ Georg Thieme Verlag Stuttgart, New York. Thieme Medical Publishers Inc., New York 1987

Price: DM 398326 pages Figures Index Hard cover ISBN 3137055016

This is the best illustrated tome on operative approaches I have seen. We are taken through the approaches from skin down to the target area, usually joint or bone, in lucid steps. The troublesome structures that have to be avoided are all displayed. Unless one wished to embark on do-it-yourself surgery this book is for the practising orthopaedic surgeon or for those studying for higher exams in orthopaedic surgery.

Basil Helal 